\title{
DAMAGE EVOLUTION AND RESIDUAL STRESSES IN PLASMA-SPRAYED ZIRCONIA THERMAL BARRIER COATING *
}

\author{
J. P. Singh, B. Nair, D. Renusch, ${ }^{* *}$ M. Sutaria, and M. Grimsditch** \\ Energy Technology Division \\ **Materials Science Division \\ Argonne National Laboratory
}

Argonne, IL 60439

January 1999

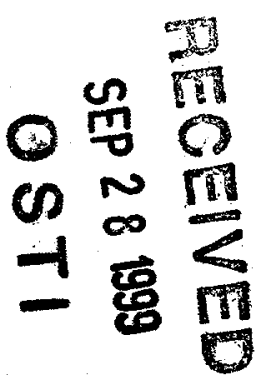

The submitted manuscript has been crealed by the University of Chicago as Operator of Argonne National Laboratory ("Argonne") under Contract No. W-31-109-ENG-38 with the U.S. Department of Energy. The U.S. Government retains for itself, and others acting on its behalf, a paid-up, nonexclusive, itrevocable worktwide license in said article to reproduce, prepare derivative works, distribute copies to the public, and pertorm publicly and display publicly, by or on behalf of the Government.

For publication in Proceedings of 23rd Annual Cocoa Beach Conference on Engineering Ceramics and Structures, American Ceramic Society, Cocoa Beach, FL, Jan. 25-29, 1999.

*Work supported by the U.S. Department of Energy (DOE), Office of Industrial Technologies, under Contract W-31-109-Eng-38. 


\section{DISCLAIMER}

This report was prepared as an account of work sponsored by an agency of the United States Government. Neither the United States Government nor any agency thereof, nor any of their employees, make any warranty, express or implied, or assumes any legal liability or responsibility for the accuracy, completeness, or usefulness of any information, apparatus, product, or process disclosed, or represents that its use would not infringe privately owned rights. Reference herein to any specific commercial product, process, or service by trade name, trademark, manufacturer, or otherwise does not necessarily constitute or imply its endorsement, recommendation, or favoring by the United States Government or any agency thereof. The views and opinions of authors expressed herein do not necessarily state or reflect those of the United States Government or any agency thereof. 


\section{DISCLAIMER}

Portions of this document may be illegible in electronic image products. Images are produced from the best available original document. 


\title{
DAMAGE EVOLUTION AND RESIDUAL STRESSES IN PLASMA-SPRAYED ZIRCONIA THERMAL BARRIER COATING
}

\author{
J. P. Singh, B. Nair, D. Renusch, M. Sutaria, and M. Grimsditch \\ Argonne National Laboratory \\ 9700 South Cass Avenue \\ Argonne, IL 60439
}

\begin{abstract}
Air-plasma-sprayed zirconia thermal barrier coatings were subjected to thermal cycling and. residual stress evolution in thermally grown oxide scale was studied by micro- and macro-ruby fluorescence spectroscopy. The macro approach reveals that compressive stress in the oxide scale increases with increasing number of thermal cycles (and thus increasing scale thickness), reaching a value of $1.8 \mathrm{GPa}$ at a scale thickness of $3-4 \mu \mathrm{m}$ (80 cycles). Micro-ruby fluorescence spectroscopy indicates that protrusions of the zirconia top coat into the bond coat act as localized areas of high stress concentration, leading to damage initiation during thermal cycling.
\end{abstract}

\section{INTRODUCTION}

Nickel-based superalloys with protective zirconia thermal barrier coatings (TBCs) are gaining wide acceptance as effective materials systems for application in turbines and other engines. The low thermal conductivity of the zirconia coatings facilitates the use of superalloys at temperatures $150-200^{\circ} \mathrm{C}$ higher than that of conventional operation. Currently, the effectiveness of these TBC systems is limited by their structural reliability and corrosion resistance under thermal cycling conditions encountered in service applications. A typical TBC system consists of a top ceramic coat and a metallic bond coat that is located between the superalloy substrate and the top coat. Residual stresses are developed in the TBCs due to thermal mismatch and oxide scale growth during processing and service. Transient thermal stresses are superimposed onto these residual stresses during thermal cycling. These stresses lead to localized damage (microcracking) at the top coat/bond coat interface. Coating failure occurs due to growth and coalescence of these microcracks. ${ }^{2,3}$ Initiation and growth of damage in the TBC is greatly influenced by interface microstructural features that result in stress concentrations at various locations. Therefore, evaluation of microstructural effects and residual stresses is critical in gaining an understanding of damage evolution and failure prediction for TBCs. Our current work focuses on measuring residual stresses in the thermally grown oxide (TGO) by ruby fluorescence spectroscopy and correlating these stresses with mechanical and chemical damage evolution during thermal cycling.

\section{MATERIALS AND METHODS}

The TBC system used for the study of damage evolution during thermal cycling is a nickelbased superalloy (Inconel alloy 617) coated with two air-plasma-sprayed layers: the metallic $\mathrm{Ni}-\mathrm{Co}-\mathrm{Cr}-\mathrm{Al}-\mathrm{Y}$ bond coat $(\mathrm{Ni} 171)$ is adjacent to the substrate, and the top coat is zirconia $\left(\mathrm{ZrO}_{2}\right)$, partially stabilized with $7 \mathrm{wt} \%$ yttria $\left(\mathrm{Y}_{2} \mathrm{O}_{3}\right)$. The superalloy substrate coupons were disk-shaped with a diameter of $1.0 \mathrm{in}$. and a thickness of $0.25 \mathrm{in}$. Thickness of the ceramic top coat was $\approx 300 \mu \mathrm{m}$ and that of the bond coat was $\approx 100 \mu \mathrm{m}$. The microstructure of the $\mathrm{ZrO}_{2}$ top coat was highly porous ( $\approx 90 \%$ dense) and contained a fine network of microcracks in the as-processed state. The metallic bond coat was denser and had a layered microstructure characterized by splats flattened with respect to the surface of the substrate. In the as-processed state, some fine cracks were present at the top coat/bond coat interface. Energy-dispersive spectroscopy (EDS) indicated no oxide formation at the interface in the as-processed state. 
The specimens were thermally cycled in air in a high-temperature bottom-drop furnace (Rapid Temperature Furnace, CM Furnaces Inc., Bloomfield, NJ) equipped with a platform that could be raised or lowered by an external electronic controller (Micristar, Model 828). During each cycle, the specimen was heated to $980^{\circ} \mathrm{C}$ in $15 \mathrm{~min}$, held at that temperature for $30 \mathrm{~min}$, and subsequently cooled by forced air for $30 \mathrm{~min}$. The specimens were intermittently (after 10-20 cycles) ground and polished to a $1 \mu \mathrm{m}$ surface finish to estimate damage introduced during the thermal cycling.

A rectangular bar was used for residual stress measurements in the TGO (at the top coat/bond coat interface during oxidation) by fluorescence spectroscopy. The thickness of the zirconia top coat was $150-200 \mu \mathrm{m}$ and that of the bond coat (VPS NiCoCrAlYHfSi) layer was $\approx 100 \mu \mathrm{m}$. The substrate was a superalloy (Mar-M-247) beam with a cross section of $3 \times 4 \mathrm{~mm}$. The specimen was isothermally oxidized for a predetermined time period at $1150^{\circ} \mathrm{C}$ in order to grow an oxide scale at the top coat/bond coat interface.

Fluorescence spectra were recorded in both macro- and micro-configurations. The spectra were excited with 50 to $100 \mathrm{~mW}$ of $476 \mathrm{~nm}$ radiation from a $\mathrm{Kr}$ ion laser and analyzed with a triple Jobin-Yvon grating spectrometer equipped with a CCD (charge-coupled device) detector from Princeton Instruments. In the macro experiments, the incident beam was focused to a spot size of about $75 \mu \mathrm{m}$ and the scattered light was collected along the surface normal with a 1.4 lens. The micro-fluorescence spectra were acquired in the backscattering geometry through a microscope that allowed the laser to be focused to $\approx 2 \mu \mathrm{m}$.

\section{RESULTS AND DISCUSSION}

Figure 1 shows a secondary electron image of the top coat/bond coat interface for the TBC specimen after 90 thermal cycles. A continuous $\mathrm{Al}_{2} \mathrm{O}_{3}$ scale (composition confirmed by EDS), $\approx 3-4 \mu \mathrm{m}$ thick, formed at the $\mathrm{ZrO}_{2}$ top coat/bond coat interface after 90 thermal cycles. Highresolution electron microscopy of the interface region suggests that damage is preferentially initiated where the $\mathrm{ZrO}_{2}$ protrudes into the bond coat. Damage in peninsular regions has been recognized as due to oxidation-induced stresses. ${ }^{4-6}$ Other than the layered microcrack structure generated within such peninsular regions, no large cracks were observed. This lends credence to the idea that spallation occurs through eventual linkage of microcracks, rather than through rapid propagation of a single crack.

Because an understanding of the stress distribution developed during scale growth is critical to knowledge of damage evolution in such peninsular regions, quantitative study of this effect is essential. This was done by residual stress measurements in an area of an isothermally oxidized specimen where the zirconia top coat protrudes into the bond coat (similar to that observed in the thermally cycled specimens; see Fig 2a). Each specific location where microruby fluorescence spectra was recorded and analyzed is indicated by an " $x$ " and a corresponding number on the photomicrograph. The residual stresses measured at these locations are shown in Figure $2 b$, plotted as a function of spatial location. The results clearly indicate that the residual hydrostatic stress is a strong function of the local interface geometry. In general, the results suggest that compressive residual stress increases with increasing inclination of the local tangent plane of the interface with respect to the substrate. Where the surface of the protrusion is nearly perpendicular to the plane of the substrate, the residual hydrostatic compressive stress is almost twice $(\approx 1.6 \pm$ $0.5 \mathrm{GPa})$ that in the troughs of the protrusions and in flat areas outside the protrusions $(\approx 0.8 \pm 0.5$ $\mathrm{GPa}$ ). This trend in stress variation was observed in all the protrusions considered in our study. However, in a similar study by Lance et al. ${ }^{7}$ on thermally cycled specimens, maximum compressive stresses were observed at the troughs of the protrusions. This difference in the location of maximum compressive stress is believed to be due to growth stress relaxation in the scale resulting from microcracking of the TGO induced during thermal cycling, leading to predominance of thermal mismatch stresses in cycled specimens.

Macro-ruby fluorescence spectroscopy analysis was used to study the evolution of residual stresses in the $\mathrm{Al}_{2} \mathrm{O}_{3}$ scale of a similar TBC specimen as a function of thermal cycles. The results indicate that the average hydrostatic compressive stress in the scale increases significantly from 


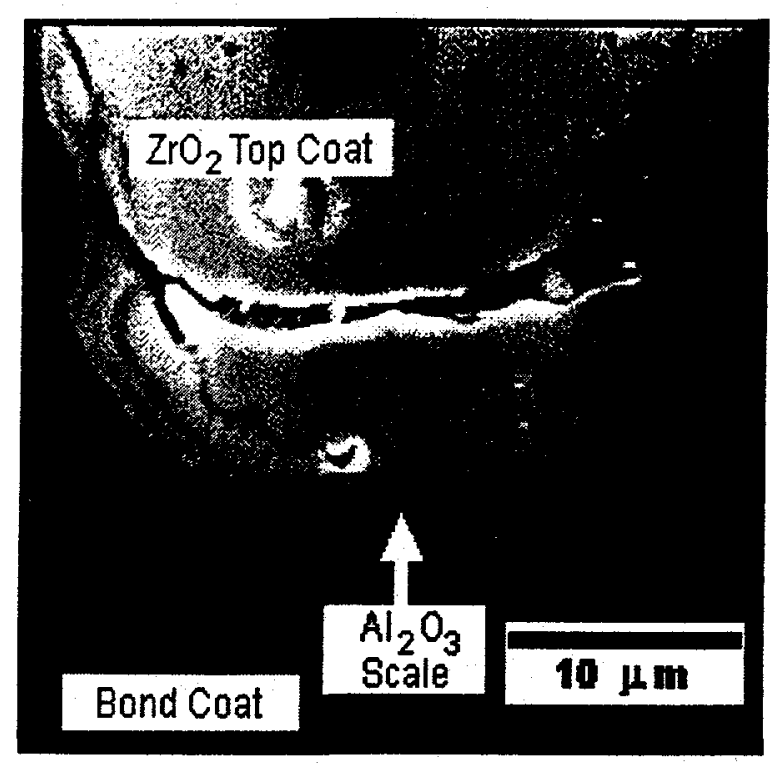

Figure 1. High-resolution secondary electron images of damage introduced by thermal cycling at the $\mathrm{ZrO}_{2}$ top coat/bond coat interface. Continuous $\mathrm{Al}_{2} \mathrm{O}_{3}$ scale at interface is $3-4 \mu \mathrm{m}$ thick.

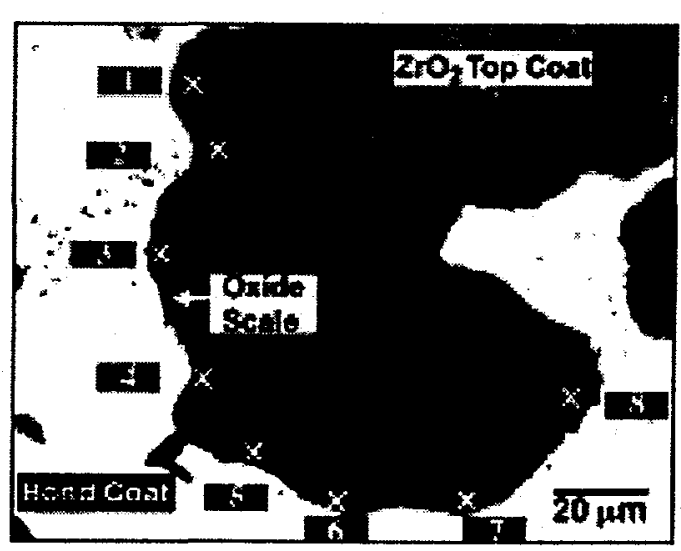

(a)

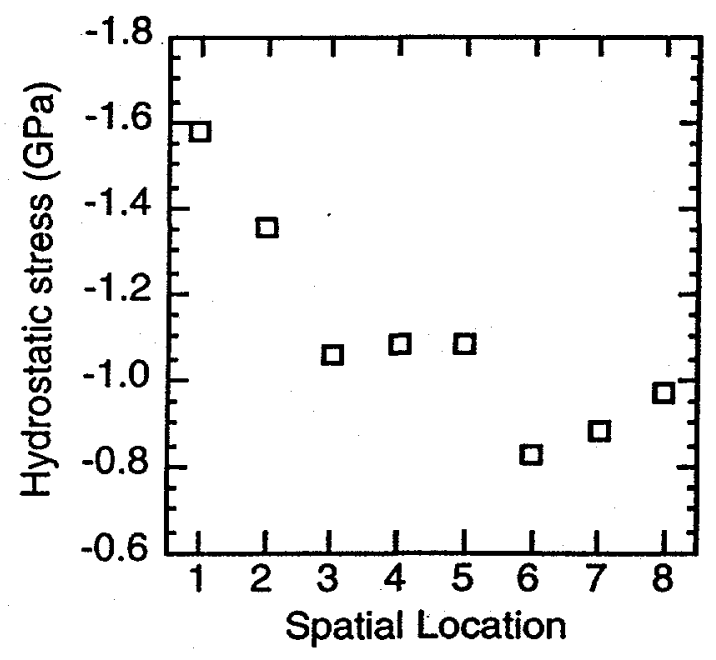

(b)

Figure 2. (a) Optical micrograph of area where zirconia top coat protrudes into the bond coat. Each location from where microfluorescence spectra was recorded is marked by an " $x$ " and a corresponding number. (b) Measured residual stress distribution in the $\mathrm{Al}_{2} \mathrm{O}_{3}$ scale around the protrusion as a function of spatial location. 


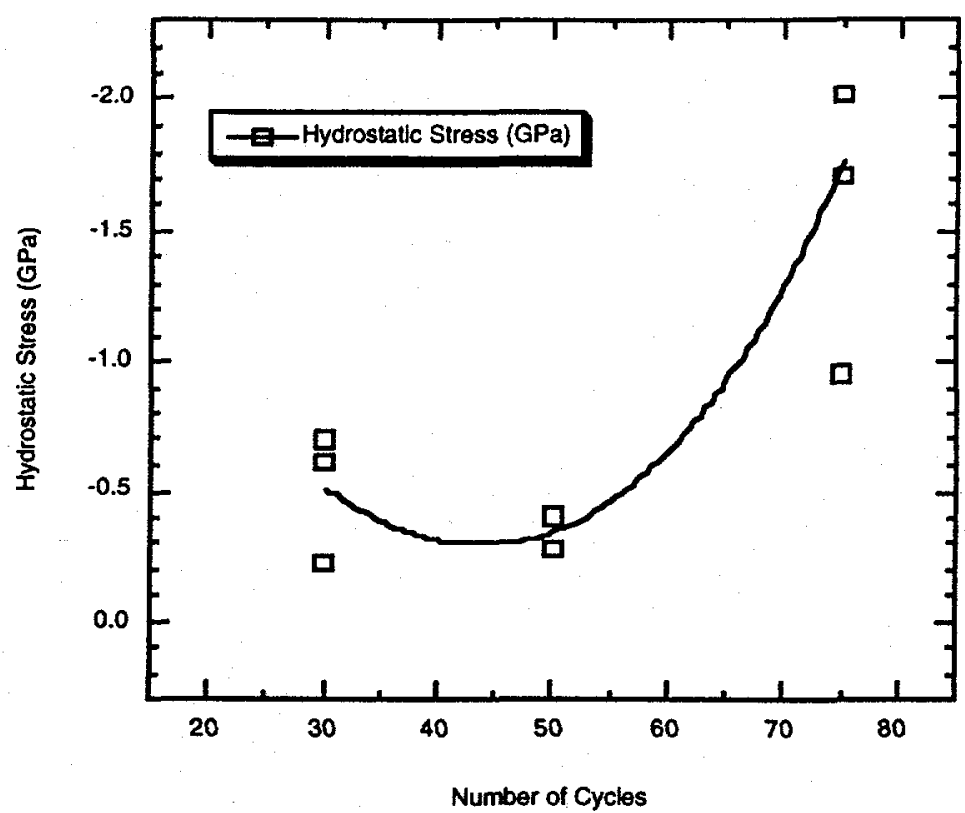

Figure 3. Residual stress in $\mathrm{Al}_{2} \mathrm{O}_{3}$ oxide scale as a function of thermal cycles in a TBC specimen measured through top coat by Raman spectroscopy.

$\approx 0.5 \mathrm{GPa}$ to $\approx 1.7 \mathrm{GPa}$ (Fig. 3) as the TBC develops damage (microcracks) during thermal cycling. This makes intuitive sense because the residual tensile forces induced in the bond coat and substrate (during processing) are counterbalanced by the compressive forces in the zirconia top coat and the scale. The magnitude of residual hydrostatic stress in the scale during thermal cycling is affected by damage in the zirconia top coat. Residual stress in the oxide scale increases with increasing number of thermal cycles: thermal cycling causes microcracking and stress relaxation in the top coat, resulting in a transfer of compressive stress to the scale. This transfer is consistent with the observed evolution of damage and mechanical properties of the top coat: both the hardness and elastic modulus decrease above 20 thermal cycles. ${ }^{7,8}$

\section{SUMMARY}

Micro- and macro-ruby fluorescence spectroscopy was used to measure the residual stresses in the thermally grown oxide scale of a zirconia thermal barrier coating. The residual stress distribution was observed to be a strong function of the local interface geometry: zirconia protrusions into the bond coat act as areas of localized stress concentrations and damage initiation. Compressive stresses as high as $1.6 \mathrm{GPa}$ were observed in protrusion regions where the scale surface is normal to the surface of the substrate. During thermal cycling, transient thermal stresses in such protrusions leads to localized microcracking: the subsequent growth and coalescence of these microcracks result in a reduction of effective elastic modulus of the top coat. This leads to stress relaxation in the top coat and a corresponding increase in compressive hydrostatic stress in the scale, as measured by micro-fluorescence spectroscopy. 


\section{ACKNOWLEDGMENT}

This work was supported by the U.S. Department of Energy (DOE), Office of Industrial Technologies, under Contract W-31-109-Eng-38.

\section{REFERENCES}

'S. M. Gupta and D. K. Gupta, "The evolution of thermal barrier coatings in gas turbine applications," J. Engr. Gas Turb. Power, 111, 301-5 (1989).

${ }^{2} \mathrm{D}$. Zhu and R. A. Miller, "Investigation of thermal high cycle and low cycle fatigue mechanisms of thick thermal barrier coatings," Mat. Sci. Engr. A, A245, 212-23 (1998).

${ }^{3}$ J. T. DeMasi-Marcin, K. D. Sheffler and S. Bose, "Mechanisms of degredation and failure in a plasma-deposited thermal barrier coating," J. Engr. Gas Turb. Power, 112, 521-26 (1990).

${ }^{4}$ A. M. Freborg, B. L. Ferguson, W. J. Brindley and G. J. Petrus, "Modeling oxidation induced stresses in thermal barrier coatings," Mat. Sci. Engr. A, A245, 182-190 (1998).

${ }^{5} \mathrm{~J}$. Cheng, E. H. Jordan, B. Barber and M. Gell, "Thermal/residual stress in an electron beam physical vapor deposited thermal barrier coating system," Acta Mater., 46 (16), 5839-50.

${ }^{6}$ M. J. Lance, J. A. Haynes, W. R. Cannon and M. K. Ferber, "Piezospectroscopic characterization of thermal barrier coatings," Ceram. Trans. Nondestructive Evaluation of Ceramics. edited by C. H. Schilling and J. N. Gray, Am. Ceram. Soc. Inc., Westerville, OH, 89, 229-237 (1998).

${ }^{7}$ J. P. Singh, M. Sutaria and M. Ferber, "Use of indentation technique to measure elastic modulus of plasma-sprayed zirconia thermal barrier coating," Ceram. Engr. Sci. Proc., 18 (4), 191-200 (1997).

${ }^{8}$ J. P. Singh, M. Sutaria and A. Chopra, "Thermomechanical behavior of plasma-sprayed zirconia thermal barrier coatings," Ceram. Engr. Sci. Proc., 19 (4), 313-322 (1998). 